\title{
DOS SERIES DE RETRATOS DE BERNARDO GERMÁN LORENTE CON UN NEXO FAMILIAR: LOS URTUSAUSTEGUI Y LOS MARQUESES DE TORRENUEVA
}

La biografía del pintor sevillano Bernardo Germán Lorente (Sevilla c. 1680/1-1757) se ha movido hasta fechas recientes dentro de los cauces marcados por Juan Agustín Ceán Bermúdez en su Diccionario... ${ }^{1}$, resultando especialmente grata por su gesto de renuncia hacia los honores de la Corte ofrecidos por Felipe V e Isabel de Farnesio: «No quiso ser pintor del rey, como se le propuso, porque no se le precisase seguir en la Corte». Se trata de una renuncia hoy completamente revisada gracias a J. Milicua, quien publicó un interesante documento fechado el año antes de la muerte del pintor, que en primera persona relata de modo suficientemente claro, aunque no todo lo explícito que sería deseable, los problemas y envidias con el pintor de Cámara Jean Ranc, que dieron al traste con su carrera palaciega ${ }^{2}$.

Por lo que respecta a su obra pictórica, el «Pintor de las Pastoras» ${ }^{3}$, como se le conocía en Sevilla en el siglo XVIII, ha arrastrado esta etiqueta cómoda y maldita, que poco a poco va siendo también revisada, eliminando de su catálogo numerosos ejemplares del tema sevillano de la Divina Pastora, para acentuar su faceta de pintor religioso en la estela de Murillo ${ }^{4}$, además de su actividad como retratista, que es la que le hizo destacar en la Corte sevillana del Lustro Real ${ }^{5}$, frente a Ranc, por el retrato del Infante Don Felipe de Borbón, único hasta ahora identificado ${ }^{6}$.

En fecha reciente (1993) han aparecido en el mercado anticuario de Madrid dos retratos españoles de la primera mitad del siglo XVIII, uno de ellos perfectamente identificado, tanto en cuanto al personaje representado - D. Luis Vicente Urtusaustegui, caballero de Calatrava y Tesorero del Ejército de Andalucía-, como en cuanto al autor de la pintura, que no es otro que el pintor Bernardo Germán Lorente, ya que el lienzo va firmado y fechado en 1735. El segundo retrato, del que en principio podría pensarse que se trata de su pareja: la esposa de D. Luis Vicente, se trata del de una mujer cuya iconografía y personalidad sólo podemos deducir indirectamente y por comparación con otro retrato suyo conservado en una serie hoy en paradero desconocido. Desde mi punto de vista dicha dama será D. a Manuela Petronila de Urtusaustegui, que es el eslabón o el anillo matrimonial que emparentó el apellido Urtusaustegui con el de Díaz de Lavandero, que detentaron los Marqueses de Torrenueva, en la Sevilla feliz de las primeras décadas del siglo XVIII. Gracias a la iconografía de esta mujer entramos a continuación a relacionar esta breve serie de dos retratos, de cuyos personajes no sabemos con seguridad qué parentesco les unió - no el de hermanos-, con otra de otros cinco retratos que atribuimos en su mayor parte al mismo Germán Lorente, a pesar de cono-

1 Diccionario Histórico de los más ilustres profesores de Bellas Artes en España. Madrid, 1800, II, p. 181. Las fechas propuestas por Ceán Bermúdez fueron corregidas por Gestoso (Véase José Gestoso y Pérez, Ensayo de un Diccionario de artífices que florecieron en Sevilla desde el siglo XIII al XVIII inclusive. Sevilla, 1908, tomo III, p. 336). Recientemente han sido recordadas por Josefa Torres Mata, «Nuevos datos sobre Bernardo Lorente Germán», en Archivo Hispalense, n. ${ }^{\circ} 212,1986$, pp. 215-222).

2 José Milicua: «Bernardo Lorente Germán. El retrato del Infante Don Felipe», en Archivo Español de Arte, 1961, pp. 313-320.

3 Julio Cavestany: «El pintor de las pastoras», en Arte Español, 1945, XV, pp. 107-111. Véase también Milicua, art. cit., p. 316, nota 6.

${ }_{4}$ Enrique Valdivieso: Historia de la Pintura sevillana. Siglos XIII-XX. Sevilla, 1986, pp. 303-307 y láms. 241-255. También Pedro A. Galera Andreu, «Pintura sevillana en Jaén: Lorente Germán y Ruiz Soriano», en Archivo Hispalense, n. ${ }^{\circ}$ 218, 1988, pp. 207-211.

5. Aurora León: Iconografía y fiesta durante el lustro Real, 1729-1733. Sevilla, 1990.

6 Milicua, art. cit. 
cerlos sólo a través de las fotografías que se publicaron en el Catálogo de la Exposición de Retratos, celebrada en Sevilla en 1910.

\section{Los retratos de la familia Urtusaustegui}

El retrato de D. José Vicente Urtusaustegui y Luyando, Zabala e Ibarra (fig. 3) ${ }^{7}$ representa a este personaje de origen vizcaíno incardinado en la burguesía ennoblecida sevillana del reinado y de la corte del «lustro real» de Felipe V e Isabel de Farnesio, de más de media figura sobre un fondo de dosel rojo y balaustrada a contraluz abierto sobre un jardín. Su porte es corpulento: viste casaca gris de amplias bocamangas con botonadura, ornada con la cruz de Calatrava, cuyo rango había obtenido por Real Cédula de 15 de octubre de $1729^{8}$. Sobre la camisa blanca, una cinta de color rosáceo pende igualmente la cruz de la Orden Militar dentro de la joya de plata y pedrería. Resulta muy interesante por razones de moda el estilo de la peluca, rizada, pero no alta, partida en el centro y recogida en pequeñas coletas que afloran a uno y otro lado del cuello. La severa expresión, las facciones rellenas y con profundas sombras marcando el perfil se dinamiza gracias al movimiento de la mano derecha, con la cual se presenta en el papel inscrito que dice: «+A d ${ }^{\text {on }}$ Luis $\mathrm{Viz}^{\mathrm{te}} /$ de Urtusauste/gui $\mathrm{g}^{\mathrm{e}} \mathrm{D}^{\mathrm{s}} \mathrm{m}^{\mathrm{s}} \mathrm{a}^{\mathrm{s}} / \mathrm{Cav}$ ro del orden de Calatrava,/ y thesorero del / $\mathrm{Ex}^{\mathrm{to}}$ de / $\mathrm{Andc}^{\mathrm{a}}{ }{ }^{9}$. En el tizón de la balaustrada va firmado y fechado: «Bern. German faciebat, año/1735». Desde un punto de vista estilístico se trata de un estimable retrato, dada la fama del pintor en este género y la escasez de muestras conservadas, en el que se aprecian las cualidades de pintor: la imprimación rojiza del fondo emerge en algunas partes; el manejo de los colores es parco y la paleta resulta igualmente de una cierta sequedad, textura terrosa en la pincelada, especialmente en los accesorios (telón, balaustrada), mostrando más empeño en el traje y, por su puesto, en las luces y matices de la cabeza. Esta, por su peinado, no puede dejar de recordar a algunos personajes contemporáneos de la Corte y de la ciencia, como Don Martín Martínez, grabado por Juan Bernabé Palomino, sobre modelo de Valerio Iriarte ${ }^{10}$. Es ilustración de su Anatomía Completa del Hombre, publicada en Madrid en 1745, con ilustraciones de Fray Matías de Irala. El personaje, según reza la estampa, era «Médico de Cámara de Su Majestad, Socio y Expresidente de la Regia Sociedad de Sevilla...», con lo que se establece un nexo con los retratos y el ambiente de Lorente.

Además de lo que declara el retrato, ¿qué sabemos del personaje? El Archivo Histórico Nacional conserva el expediente de información y pruebas para el ingreso en la Orden de Calatrava ${ }^{11}$. Por él sabemos que fue hijo de Luis de Urtusaustegui y de Angela Zabala, nacido en Gordejuela (Vizcaya), donde fue bautizado el 28 de enero de 1704. Como pruebas de nobleza adujo las armas en piedra del apellido Zabala o Zaballa, con una cruz grande partiendo el campo, con cuatro paneles o corazones en los troncos y una faja o bordadura con ocho aspas. Una Real Cédula del 15 de octubre de 1729 le otorgaba el honor del hábito y cruz de Calatrava, contando 25 años. A los 31 fue retratado por Bernardo Germán Lorente en

7 Óleo/lienzo. Mide 1,04 x 0,83. Restaurado y forrado en 1993. Adquirido a los Marqueses de Montesión.

8 Vicente Cadenas y Vicent: Caballeros de la Orden de Calatrava. Siglo XVIII.

9 «A Don Luis Vizente de Urtusaustegui guarde Dios muchos años. Caballero del Orden de Calatrava, y thesorero del Exercito de Andalucia».

10 Alfonso E. Pérez Sánchez: "Valerio Iriarte "Addenda et corrigenda" al Catálogo del Museo del Prado», en Boletín del Museo del Prado, III, n. ${ }^{\circ}$ 9, 1982, p. 155.

${ }_{11}$ Cadenas y Vicent, op. cit, 198... pp. 
un retrato que aparenta mayor edad, quizá por el acentuado sombreado de la barba, las comisuras y los ojos.

La pareja de este retrato, que no lo es más que desde un punto de vista familiar muy vago, representa a una mujer ${ }^{12}$ de mayor edad según vemos, pero que de no conocer los años de D. Luis Vicente podríamos pensar que hubiera sido su esposa (fig. 4). La dama aparece frontalmente, con la cabeza ligeramente inclinada hacia su izquierda, lado al que se proyectan las sombras de la composición. Al paisaje abierto y al telón de fondo el pintor añadió un pedestal arquitectónico con un almohadón de terciopelo rojo, destinado a apoyar el brazo. Es un retrato de extraordinaria economía de medios, predominantemente rojizo y terroso en los fondos, donde el blanco y el azul iluminan y matizan las telas y el paisaje. La cabeza destaca luminosa con su peluca corta blanca entre el rojizo telón y el vestido de terciopelo rojo bordado con rameados y flores blancas y verdes. El detalle de estos elementos se extiende tanto a las joyas que decoran el corpiño, como a la minuciosidad del tratamiento de los encajes de las mangas. El amplio vuelo de la falda, la espesura del terciopelo rojo y sus tornasoles luminosos recuerdan los maestros franceses, especialmente Jean Ranc y sus seguidores, alejándose de este modo de la tradición castiza representada en Madrid por Miguel Jacinto Meléndez, y del murillismo sevillano.

¿Quién es la retratada? Gracias al Catálogo de la Exposición de Retratos Antiguos celebrada en Sevilla en abril de $1910{ }^{13}$ podemos, si no saberlo con plena seguridad, al menos aproximarnos, puesto que el retrato n.. 104 representa a una mujer, en la misma pose y con las variantes de presentar todo el vestido floreado y un rostro quizá más joven y más jovial, como si fueran casi madre e hija (fig. 5). Pero no hay que descartar que puedan ser la misma persona por la razón de que en el transcurso de la limpieza del retrato ahora aparecido se procedió a eliminar numerosos repintes que dulcificaban y ocultaban el verdadero y originario rostro interpretado por Germán Lorente, al igual que el telón de fondo.

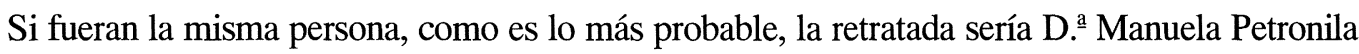
de Urtusaustegui, según el Catálogo de 1910, marquesa de Torrenueva ${ }^{14}$. Efigiada a los 45 años más o menos. A través de la fotografía de la que llamaremos segunda versión no parece que el retrato, que no conozco directamente, tenga letreros identificativos. Sí los tienen, aunque tampoco sean legibles en las fotografías en blanco y negro de 1910, algunos de los restantes cuatro lienzos que representan distintos miembros de la familia de los Torrenueva, casi todos probablemente de una misma mano, que para mí no hay duda que debe ser la de Bernardo Germán Lorente.

12 Óleo/lienzo. 1,04 x 0,83. Restaurado, eliminación de repintes. 1993.

13 Redactado por J. Gestoso y Pérez, y editado en la oficina tipográfica de Blanco y Negro. Madrid. MCMX, con fotografías de J. Barrera.

${ }^{14}$ A pesar de la similitud de apellidos D. Luis Vicente y D. ${ }^{a}$ Manuela Petronila eran hijos de distintos padres. D. ${ }^{a}$ Manuela nació en Sevilla el 5 de enero de 1690, siendo hija de José Urtusaustegui, natural de Azcaray (Vizcaya) (sic), que testó en Sevilla el 28 de diciembre de 1697, dejando tres hijos: José, Manuela y Cipriano. Su madre se llamó Manuela Fernández Hidalgo, que testó en Sevilla el 12 de octubre de 1703. Como se ve entre los herederos no había ningún Luis Vicente, quien era natural de Gordejuela e hijo de Luis y del Angela Zabala, y había nacido en 1704. Se llevaban 14 años de diferencia. El hecho de que los retratos hayan aparecido juntos y la similitud de apellido revelan algún desconocido parentesco: ¿tía y sobrino? Así aparece identificada recientemente por Eduardo Ybarra Hidalgo: «Los ilustres antepasados de una casa en ruinas», dentro del catálogo de la exposición La Casa de los Artistas, Museo de Bellas Artes de Sevilla, 25 de octubre a 23 de noviembre. Sevilla, 1997, p. 41. 

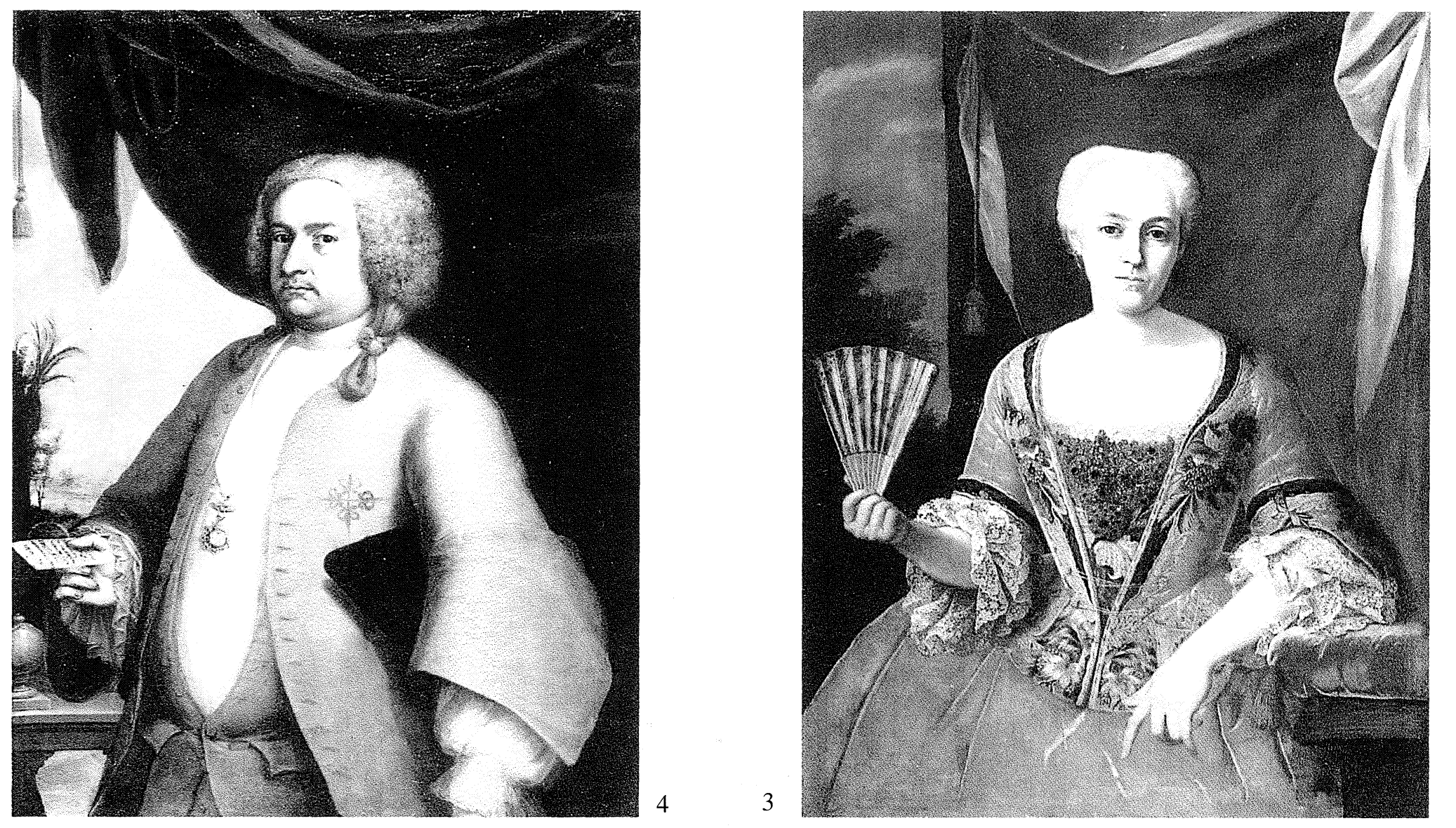

Figura 3. Don José Vicente Urtusaustegui y Luyando, Zabala e Ibarra, firmado y fechado en 1735.

Figura 4. D. ${ }^{\underline{a}}$ Manuela Petronila de Urtusaustegui, Marquesa de Torrenueva. Madrid, colección privada. 


\section{Los retratos de los Marqueses de Torrenueva}

En la Exposición de 1910, como pertenecientes al Marqués de Torrenueva, comparecieron los siguientes retratos de antepasados suyos que, al hilo de la descripción del catálogo, quiero completar y comentar utilizando el orden inverso al del citado Catálogo, que es sin embargo el correcto orden cronológico.

Con el número 105 se presentaba al «Excelentísimo Sr. Mateo Pablo Díaz de Lavandero, primer marqués de Torrenueva. De pie, más de medio cuerpo, tam(año) nat(ural). Esc. española. Siglo XVIII. 1,24 x 1,03.» (fig. 6). La fotografía permite ver la corpulenta figura sobre un fondo oscuro, con una abertura hacia la luz, en pose de tus cuartos hacia su izquierda. Viste una rica casaca bordada con profusión en las solapas, bocamangas y faldón, y encajes en los puños. El brazo izquierdo parece descansar sobre un pedestal y lleva en la mano unos guantes, mientras que en la mano derecha porta un papel escrito, que sin duda, ayuda a identificarlo como tal Marqués de Torrenueva. La peluca amplia, larga, partida con raya en el centro y rizada es la del reinado de Felipe V. Luce al cuello, colgada de un cinta, la cruz de Caballero de Santiago. El expediente para obtener dicha condecoración lo había iniciado en 1734. Por él sabemos que su segundo apellido era Martín y que había nacido en Pelahustán (Toledo) el 10 de julio de 1681 . Como prueba de nobleza adujo haber sido nombrado Marqués de Torrenueva ${ }^{15}$, título concedido por Felipe V en Sevilla el 15 de marzo de 1732, y ser Tesorero Mayor del Consejo de Hacienda. El Elenco de Grandeza y Títulos nobiliarios de España señala además que nuestro hombre fue Veinticuatro de Sevilla y Alguacil Mayor de la Inquisición, sin más datos ni fechas ${ }^{16}$. El hecho de lucir la Orden de Santiago llevaría la fecha del retrato al año 1735, el mismo del retrato de D. Luis Vicente de Urtusaustegui. La edad representada por el retratado ronda los cincuenta años, quizá alguno más. Es muy probable que lo pintara entre la concesión del título y la del Hábito (1732-1735).

La biografía de nuestro personaje puede completarse con datos sacados de otra información y pruebas de ingreso en la Orden de Santiago, abierta en 1738 a favor de D. Antonio María Díaz de Lavandero y Urtusaustegui, Capitán de Infantería y Alférez de las Reales Guardias de lnfantería Española, según la prueba de nobleza, e hijo de D. Mateo Pablo y de su mujer D. a Manuela Petronila de Urtusaustegui casados en Sevilla el 5 de mayo de 1709. En buena lógica este Don Antonio María Díaz de Lavandero y Urtusaustegui, II Marqués de Torrenueva, que perseguía el hábito de Santiago en 1738, debe ser el número 103 del Catálogo de 1910 (fig. 7). Como el resto de los retratos masculinos de la serie, representa a un hombre joven de más de medio cuerpo, en pose de tres cuartos hacia su izquierda, recortado sobre el fondo de paisaje y cortinajes al que se ha añadido un escudo heráldico. Sobre la camisa blanca luce casaca de terciopelo con finos bordados. Luce una gran peluca, más alta que la de su padre y adopta una postura chulesca con el brazo derecho en jarra a la cadera, mientras sujeta un sombrero entre el brazo y el costado izquierdo, en cuya mano lleva guantes y un papel, de nuevo ilegible, si es que estuvo escrito, puesto que el catálogo lo identifica como D. Antonio Díaz de Lavandero y Piscatori ${ }^{17}$. No lleva condecoración alguna, salvo la

15 Vicente Cadenas y Vicent. Caballeros de la Orden de Santiago. Siglo XVIII. Tomo III. Años 1731-1745. Madrid, 1978, pp. 34-35, (A.H.N., sig. 2.458, n. ${ }^{\circ} 775$ ).

16 Instituto Salazar de Castro (C.S.I.C.). Madrid, 1989. Para más datos, véase el artículo de Ybarra Hidalgo.

17 Cadenas y Vicent, Op. cit., 1978, pp. 90-91. (A.H.N. sig. 2.549, expediente n. ${ }^{\circ} 848$ ). El apellido estaba introducido en la Corte; una Laura Piscatori era azafata de la reina Isabel de Farnesio y encargada de la conducción del vino de la reina (Cfr. Teresa Lavalle Cobo-Iriburu: El mecenazgo de Isabel Farnesio, Reina de España. Tesis Doctoral (inédita) de la Universidad Autónoma de Madrid, 1994, tomo I, p. 101). 
cruz de Santiago en el escudo, lo que permitiría situar la obra antes de 1738 y aproximarla hacia la fecha de 1735 . Una de las razones que nos empujan a proponer el nuevo nombre es el del escudo de armas que luce el retrato: en él el último cuartel incluye las armas de los Zabala, aducidos por D. Luis Vicente de Urtusaustegui en su probanza de la orden de Calatrava. Según Cadenas y Vicent, Don Antonio María Díaz de Lavandero nació el 2 de agosto de 1725 (sic) ${ }^{18}$, cuando sus padres se casaron en 1709. Es evidente que si el retrato fue pintado antes de 1738, el joven no representa 13 años, sino muchos más, quizá diez más, hasta veintitrés.

En el Catálogo de 1910, con el apellido de Piscatori que, como materno, se le otorgaba al II marqués de Torrenueva se identificaba al retrato número 102: «Doña María Teresa Piscatori y Varona, marquesa de Torrenueva. De pie, de más de medio cuerpo. tam. nat. Esc. Española. Siglo XVIII. 1,25 x 1,03» (fig. 8). El lienzo carece de letreros y de identificación. Por la edad que representa, una joven que ronda los veinte años o menos, debió de ser la esposa del II marqués, no la madre como se deduce de las identificaciones que se propusieron. Además la composición y su pose guarda absoluta simetría con el retrato de D. Antonio María. Es el único de los retratos representado al aire libre con claros a ambos lados de una espesura arbolada que sirve para recortar la figura bajo una luz lateral intensa, quizá menos dura que la muestra la foto en blanco y negro. Como todos los restantes retratos, está efigiada de más de medio cuerpo, en tres cuartos hacia su derecha, pero mirando al frente. Dentro del estrecho corpiño, la anatomía se adivina pequeña y delicada, casi como el gesto de coger u ofrecer el ramillete de flores de la mano derecha. A pesar de la expresión algo petrificada, el vestido es una bella muestra de terciopelo y seda bordada de color claro, completado con aderezos de joyas en el pecho y en el peinado, recogido y muy pegado a la cabeza, y con el abanico cerrado en la mano izquierda.

A través del apellido puede verse que se trata de una joven de origen italiano. Como indicio de su origen posible tenemos el expediente que en 1739 Francisco Piscatori y Baroni (no Varona), nacido en Madrid el 11 de febrero de 1721, hijo de Luis Piscatori y de Angela Baroni, naturales de Parma, inició para probar su nobleza en la Orden de Santiago. Curiosamente, sus méritos eran ser Alférez en los Reales Guardias de Infantería ${ }^{19}$, es decir, allí mismo donde el II marqués de Torrenueva era capitán. A falta de comprobación, este Francisco Piscatori debió ser hermano de la II marquesa y por tanto cuñado de D. Antonio María Díaz de Lavandero.

Creo que estos cuatro retratos de los primeros marqueses de Torrenueva deben ser tenidos como obras de Bernardo Germán Lorente, tomando como punto de referencia los otros dos de los Urtusaustegui, por las razones de semejanza y parentesco entre ellos, y considerados de fecha próxima al año 1735, en que está firmado y fechado el de D. Luis Vicente de Urtusaustegui. No tengo la misma convicción sobre el quinto retrato de la serie Torrenueva, el que representa a Don Antonio Díaz de Lavandero y Piscatori (fig. 9) (Catálogo Exposición 1910, n. 101): Representa a un mozalbete que rondará quizá los diez años, luce una casaca con galones en las bocamangas y mangas y una peluca corta con bucles laterales más propia del reinado de Fernando VI e incluso del de Carlos III. La apostura grácil y la expresión risueña dista de la severidad de los rostros de Lorente Germán. La composición recuerda a ciertos retratos de la década 1750-1760.

\footnotetext{
18 Cadenas y Vicent, op. cit., 1978, pp. 90-91.

19 Cadenas y Vicent, op. cit., 1978. pp. 139-140. sig. 6.921, expediente n. ${ }^{\circ} 911$.
} 

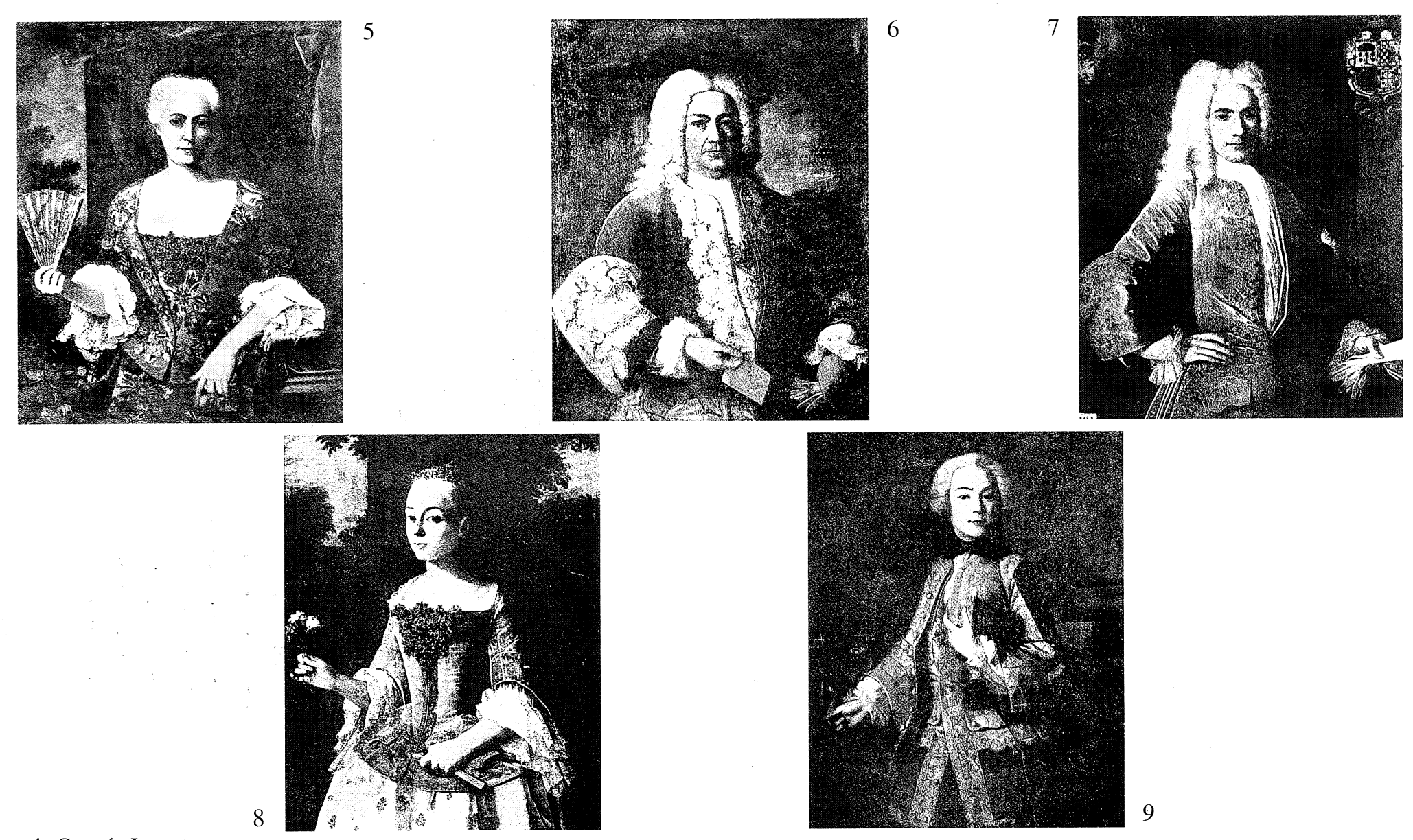

Bernardo Germán Lorente

Figura 5. D. ${ }^{\underline{a}}$ Manuela de Urtusaustegui, Marquesa de Torrenueva, ca. 1735.

Figura 6. D. Mateo Pablo Díaz de Lavandero, I Marqués de Torrenueva, ca. 1735.

Figura 7. D. Antonio María Díaz de Lavandero y Urtusaustegui, II Marqués de Torrenueva, ca. 1735-1738.

Figura 8. D. $.^{a} M .^{\underline{a}}$ Teresa Piscatori y Varona, II Marquesa de Torrenueva.

Figura 9. ¿Bernardo Germán Lorente? D. Antonio Díaz de Lavandero y Piscatori, ca. 1750. Sevilla. Antigua colección de los Marqueses de Torrenueva. 
En el conjunto de la obra de Bernardo Germán Lorente estos retratos suponen un notable enriquecimiento de su catálogo y de su actividad como retratista, actividad en la que, de creer a Ceán Bermúdez, destacó durante la estancia de la Corte en Sevilla entre 1729 y 1733, retratando entonces al Infante Don Felipe a plena satisfacción de la reina Isabel de Farnesio, quien le regaló las estampas de las batallas de Alejandro de Charles Le Brun, grabadas por Audran, «que acababan de venir de Francia» ${ }^{20}$. Este único retrato citado por Ceán, identificado con el que publicó Milicua en la colección Gabriel Coll de Barcelona ${ }^{21}$, ha sido el único testimonio de la labor retratística de Lorente hasta hoy, en la que ha comenzado a valorarse no sólo su pintura religiosa sino sus trampantojos y sus pinturas de género ${ }^{22}$.

Aunque Lorente se dedicó sobre todo a la pintura religiosa, de carácter devocional y popular, especialmente el tema de la Divina Pastora ${ }^{23}$, y también en series conventuales, como la contratada en 1743 para la Cartuja de Jerez ${ }^{24}$, la consideración de estas temáticas en la estela artística de Murillo le ha restado interés, a pesar de alcanzar cotas de excelente calidad y dignidad como lo muestran el San Fernando de colección particular de Sevilla. Ello unido a la escasez de retratos suyos conservados y a la tradición de Ceán que sustentó su fama precisamente en este género, en el prestigio conseguido en la Corte de Sevilla y en la fábula de la voluntaria renuncia al nombramiento de Pintor del Rey para no tener que abandonar Sevilla 25 han distorsionado la valoración técnica de Germán Lorente, que Milicua trató de equilibrar utilizando fuentes contemporáneas como las del Conde de Aguila: «... se ha granjeado una reputación a que no corresponde su dibujo, su invención ni la extravagancia de las actitudes de sus figuras y caracteres» ${ }^{26}$. Los retratos ahora publicados a pesar de sus aproximaciones al gusto francés impuesto por J. Ranc son prueba de lo afirmado por el Conde de Aguila. Su comparación con obras coetáneas de Alonso Miguel de Tovar, como el Retrato de niña (Colonia, Museo Wallraf-Richartz, 1732), por citar al otro sevillano de éxito en la corte de Felipe $\mathrm{V}$ e Isabel de Farnesio, revela una cierta sequedad en el trazo y cierta pobreza o limitación de los procedimientos técnicos de cara a la permanencia del colorido devorado por los fondos, lo que «perjudica más o menos a la totalidad de la superficie pictórica, enturbiándola y anulando matices y sensaciones», según Milicua.

ISMAEL GUTIÉRREZ PASTOR Universidad Autónoma de Madrid

${ }^{20}$ Ceán Bermúdez, Diccionario... 1800, II, pp. 181-182.

21 José Milicua, art. cit.

22 En los últimos años la figura de B. G. Lorente ha merecido la atención de Enrique Valdivieso, op. cit., 1986, pp. 303-307. y láms. 251-255, pero no aporta novedades en el tema del retrato. Algunos datos familiares sobre Lorente se publican el Fuentes para la Historia del Arte Andaluz I. Noticias de pintura (1700-1720). Prólogo y dirección de la obra Jesús M. Palomero Páramo. Autor: Fernando Quiles García. Sevilla, 1990, pp. 135-140. A partir de el Trampantojo con Baco del Museo del Louvre, recientemente le han sido atribuidas dos vanitas en el catálogo de la sala de subastas Castellana 150. Subastas de Arte S.A. Madrid, 19 de mayo de 1998: n. 113, Vanitas con Calavera (óleo/lienzo, 65 x $53,5 \mathrm{~cm}$.) y n. ${ }^{\circ} 103 \mathrm{~A}$, Vanitas con joyero y reloj de arena (óleo/lienzo, $65 \times 53,5 \mathrm{~cm}$.), de calidad diferente a las de Germán Lorente, aunque obras españolas y anónimas del siglo XVIII.

23 Julio Cavestany, Marqués de Moret, art. cit.

${ }^{24}$ Cfr. Ana María Arandal Bernal: «Obligaciones de lienzos de Bernardo Germán Lorente para la cartuja de Jerez», en Atrio. Revista de Historia del Arte, n.o 1, Sevilla, 1989, pp. 125-126.

${ }_{25}$ Véase la crítica en Milicua, art. cit., pp. 317 y ss., sustentado en una carta del pintor al Secretario de la Academia Ignacio de Hermosilla, fechada en 1758.

${ }^{26}$ Cfr. Milicua, art. cit., p. 316, nota. 6. Sobre la diversidad de intereses literarios y pictóricos de Germán Lorente puede verse el artículo de Fernando Queiles, «En torno a las posibles fuentes utilizadas por Bernardo Germán Lorente en su pintura: Análisis de la Biblioteca y de la Pinacoteca de su propiedad», en Atrio. Revista de Historia del Arte, 7 (1995), pp. 31-43, donde re-estudia el inventario de 1738 realizado a la muerte de la esposa del pintor. 